\title{
Evaluating antenatal breastmilk expression outcomes: a scoping review
}

\author{
Imane Foudil-Bey ${ }^{1,2}$, Malia S. Q. Murphy ${ }^{1}$, Sandra Dunn ${ }^{1}$, Erin J. Keely ${ }^{3,4,5}$ and Darine El-Chaâr ${ }^{1,6,7^{*}}$
}

\begin{abstract}
Background: Antenatal breastmilk expression (aBME) is recommended by some healthcare providers to improve lactation, breastfeeding, and newborn outcomes, particularly for women with diabetes as they face unique challenges with breastfeeding. However, there is limited evidence of the potential harms and benefits of this practice. Our objective was to conduct a scoping review to map the literature describing maternal and newborn outcomes of aBME.

Methods: We searched Medline, Embase, CINAHL, Cochrane Database of Systematic Reviews, British Library ETheses Online Services (EThOS) database, OpenGrey, and Clinical trials.gov from inception to January 2020. Studies in English that reported on the effect of aBME on maternal and newborn outcomes, and the experiences of women who have engaged in the practice were included for screening. Titles, abstracts, and full-text articles were screened by two independent reviewers. A critical appraisal and clinical consultation were conducted. Key findings were extracted and summarized.
\end{abstract}

Results: We screened 659 studies and 20 met the inclusion criteria. The majority of included studies $(n=11,55.0 \%)$ were published after 2015, and seven (35.0\%) originated from Australia. Ten (50.0\%) studies provided data on highrisk obstetrical populations, including those with diabetes $(n=8)$, overweight or obesity $(n=1)$, and preeclampsia $(n=1)$. Commonly reported outcomes included breastfeeding status at discharge or follow-up, mode of delivery, newborn blood glucose, and time to establishing full lactation. Maternal experiences were related to challenges with aBME, confidence and mastery, perceived impact, security and altruism, learning and resources, and physical symptoms as a result of aBME. The critical appraisal demonstrated limited high-quality evidence surrounding aBME.

Conclusions: Our findings demonstrate increasing interest in the safety, efficacy, and acceptability of aBME. Existing studies are heterogenous with variable research questions, outcomes, study designs, and methodology. The recommendations made in this review can be used to help inform future studies evaluating aBME.

Keywords: Pregnancy, Colostrum, Antenatal breastmilk expression, Breastfeeding, Antenatal breast expression

\footnotetext{
* Correspondence: delchaar@toh.ca

'OMNI Research Group, Clinical Epidemiology Program, Ottawa Hospital Research Institute, Ottawa, Canada

${ }^{6}$ Department of Obstetrics and Gynecology, University of Ottawa, Ottawa,

Canada

Full list of author information is available at the end of the article
}

(c) The Author(s). 2021 Open Access This article is licensed under a Creative Commons Attribution 4.0 International License, which permits use, sharing, adaptation, distribution and reproduction in any medium or format, as long as you give appropriate credit to the original author(s) and the source, provide a link to the Creative Commons licence, and indicate if changes were made. The images or other third party material in this article are included in the article's Creative Commons licence, unless indicated otherwise in a credit line to the material. If material is not included in the article's Creative Commons licence and your intended use is not permitted by statutory regulation or exceeds the permitted use, you will need to obtain permission directly from the copyright holder. To view a copy of this licence, visit http://creativecommons.org/licenses/by/4.0/. The Creative Commons Public Domain Dedication waiver (http://creativecommons.org/publicdomain/zero/1.0/) applies to the data made available in this article, unless otherwise stated in a credit line to the data. 


\section{Background}

The World Health Organization, Public Health Agency of Canada, Health Canada, Canadian Pediatric Society, and the Breastfeeding Committee for Canada recommend exclusive breastfeeding to 6 months of age and up to 2 years of life and beyond with appropriate introduction of solid foods [1-5]. Exclusive breastfeeding is defined as the receipt of solely human milk (infant breastfeeds or receives expressed or donor milk), as well as oral rehydration solutions and syrups (vitamins, minerals, medicine) if needed [6]. Clinical practice guidelines recommend that breastfeeding be initiated as soon as possible after birth as it provides many well accepted benefits to infant and maternal health [7-10].

Initiation of breastfeeding in hospital can be challenging in situations where the normal process of lactogenesis (milk production) or milk transfer to the newborn is delayed or impeded. Most women experience copious milk production 2-3 days postpartum (lactogenesis II) [8]; however, women with diabetes in pregnancy have been shown to experience a delay or absence of this process [8,9]. Newborns of mothers with higher risk pregnancies (i.e. diabetes, hypertension, epilepsy, or other chronic diseases in pregnancy) have an increased risk of developing neonatal complications requiring admission to the neonatal intensive care unit (NICU). This may lead to prolonged separation of the newborn from its mother which may also impede breastfeeding initiation. Additionally, newborns of mothers with diabetes are at risk of hypoglycemia directly after birth and often require infant formula or intravenous glucose [7], which may interfere with breastfeeding initiation and consequent maintenance [11]. In such cases, the use of breastmilk may be needed to supplement feeding, especially since colostrum has been shown to be more effective at stabilizing blood glucose than infant formula [12]. In scenarios where the production of breastmilk immediately after birth may be difficult, antenatal breastmilk expression (aBME) may be a feasible intervention to encourage storage of colostrum for postpartum use [13-15].

Antenatal breastmilk expression (aBME) has demonstrated potential to hasten lactogenesis II [16], decrease postpartum breast engorgement, avoid the need for breastmilk substitutes (infant formula), improve blood glucose stabilization in newborns at risk of hypoglycemia $[15,17,18]$, and increase exclusive breastfeeding maintenance up to 6 months postpartum [10]. However, the association between antenatal breast stimulation and oxytocin release raises concern about the possible induction of preterm labour or miscarriage $[15,19,20]$. Findings from observational studies suggest that mothers with diabetes who engage in aBME may be at increased risk of preterm labour and neonatal admission to the NICU $[13,20]$. In 2017, Forster et al. published the first randomized control trial (RCT) evaluating the safety and efficacy of aBME in mothers with diabetes [21]. Based on their primary outcome of newborn admission to the NICU, the trial did not report any evidence suggesting that aBME is harmful in low risk women with diabetes [21]. Although aBME is widely implemented as part of lactational and maternity support programs [22-24], evidence evaluating its safety and efficacy has largely stemmed from small observational studies with methodological limitations. A synthesis of the literature is warranted to inform clinical decision-making and future research.

Our objective was to conduct a scoping review to summarize and appraise previous approaches to evaluating maternal and newborn outcomes associated with aBME. The scoping review methodology was suitable as it allowed the authors to include multiple study designs and explore a broad clinical question [25].

\section{Methods}

\section{Sources}

This review was registered on Open Science Framework [26] and the protocol has been described in detail elsewhere [27]. Research ethics board approval was not required due to the nature of the study methodology. Our methodology was developed using a multi-step approach proposed by the Joanna Briggs Institute [28] in conjunction with the seminal scoping review frameworks [29, 30]. Our approach included: identification of the research question, identification of relevant studies, selection of studies, charting of data, critical appraisal, summary of results, and clinical consultation.

The development of our search strategy was an iterative process and was conducted in consultation with a medical librarian. The finalized search strategy is provided in the Additional file 1. Our search criteria were applied to the following electronic databases: Medline (OVID), Embase (OVID), CINAHL (EBSCOHost), Cochrane Database of Systematic Reviews (OVID), British Library E-Theses Online Services (EThOS) database, and OpenGrey. Clinical trials.gov was searched for any ongoing trials. We ran our first search on June 26, 2019 and ran a second search in January 2020 to ensure that studies published up to December 31, 2019 were captured. Records were exported from each database and uploaded to the Covidence webbased software platform [31]. Thereafter, duplicate citations were removed.

\section{Study selection}

Eligible studies included primary research on pregnant women (population) that evaluated maternal (including 
maternal experiences and perspectives, maternal health outcomes, aBME outcomes, and breastfeeding outcomes) or newborn outcomes (concept) following aBME (context). Due to the anticipated small number of studies on this topic, no limits were placed on the geography, environment, or timeframe. Studies unavailable in English, or for which the full-text articles could not be retrieved were excluded.

Title, abstract, and full text screening were conducted by two independent reviewers (IFB and MSQM). If titles and abstracts met the minimum inclusion criteria, the corresponding studies proceeded to full text review. Full texts were imported and screened in further detail for eligibility by the two reviewers. When consensus was not reached, a third, independent reviewer was consulted (DEC). The reference lists of included articles were screened for any publications that were missed by the electronic database search. The reference lists of secondary literature that were not included in our study but were retrieved from our search strategy were also screened to identify primary studies that may have been missed.

Key concepts and bibliometric data were independently extracted from all included articles by the two independent reviewers (IFB and MSQM) using a data collection form designed by the two reviewers. A template of the data collection form is provided in the Additional file 2. Although we include our assessment of all studies captured by our search strategy, we caution readers regarding the interpretation of the results of historical studies, such as those published in the 1940s and 1950s, as the research questions, study designs and study interventions are notably different than those of more recent investigations.

A critical appraisal was conducted by two independent reviewers (MSQM and SD) using the Mixed Methods Appraisal Tool (MMAT) - Version 2018 [32]. The MMAT is designed to assess the validity and strength of five study types: qualitative research, RCTs, nonrandomized studies, quantitative descriptive studies, and mixed methods studies. Articles are assessed based on reviewer responses to five questions specific to each study type. Responding with 'no' or 'can't tell' to any of the rating criteria for a given study design indicates that the study does not report appropriate information related to the criterion, or that the presented information is unclear. An overall score for each article is not given; rather, authors provided comments to support their ratings for each criterion. For the purpose of summarizing the results of the critical appraisal, we have provided numerical values that represent the number of 'yes' responses for each included article.

A clinical expert (EJK) was consulted to identify potential additional sources of information and provide further insight into the clinical applicability of the scoping review. The clinical expert provided unique perspectives using their clinical experience that guided the discussion. The clinical consultation allowed the authors to share preliminary data, guided interpretation of the results, and identified appropriate knowledge translation and dissemination strategies [30].

\section{Results}

A total of 659 studies were identified by our search strategy. One hand-picked study that was not identified by our search was included, and five were identified from the reference lists of included studies. Following removal of 201 duplicates, 464 records remained for title and abstract screening. Three hundred eighty-three titles and abstracts did not meet the minimum inclusion criteria and 81 proceeded to full-text screening. Upon full-text review, 61 articles were excluded due to unavailability of the full-text, incorrect intervention, incorrect source of data, duplicate, or reporting on outcomes unrelated to aBME. A total of 20 full-text articles met the inclusion criteria and were therefore included in the scoping review. A summary of the titles, abstracts, and full texts reviewed in the course of this review is provided in Fig. 1.

Included studies were published between 1946 and 2019. Eleven $(55.0 \%)$ were published within the last 5 years (2015-2019) [21, 24, 33-41]. Included studies originated from six countries: Australia $(n=7)[13,21,24$, 33-36], New Zealand $(n=1)$ [42], the United Kingdom $(n=5)$ [20, 39, 43-45], Sweden $(n=1)$ [46], United States $(n=3)$ [37, 38, 47], and India $(n=3)[16,40,41]$. Three dominant research groups were identified; Forster et al. [13, 21], Demirci et al. [37, 38], and Casey et al. $[35,36]$, have each published two studies included in our review. Of note, the three independent studies published in India had very similar sample sizes, study objectives, and interventions [16, 40, 41].

A detailed summary of the studies included in this scoping review is provided in Table 1 . This review included one quality improvement study [33], two case studies/series [38, 43], four qualitative and/or cross sectional survey studies of the knowledge, attitudes and experiences of women engaging in aBME [34, 35, 37, 39], three observational cohort studies $[20,36,46]$, and ten interventional studies [13, 16, 21, 24, 40-42, 44, 45, 47] including one RCT [21]. Sample sizes of included studies ranged from 1 to $60(n=8)[13,34,35,37,38,42,43$, 47], 80-230 $(n=8)[16,20,24,33,40,41,44,45]$, and $300-690(n=4)[21,36,39,46]$ participants.

Whereas ten (50.0\%) studies examined aBME practices in the general obstetrical population [16, 24, 34, 37, 40, 41, 44-47], and ten studies (50.0\%) reported on maternal or newborn outcomes as they related to high-risk populations including women with diabetes $(n=8)[13,20$, 


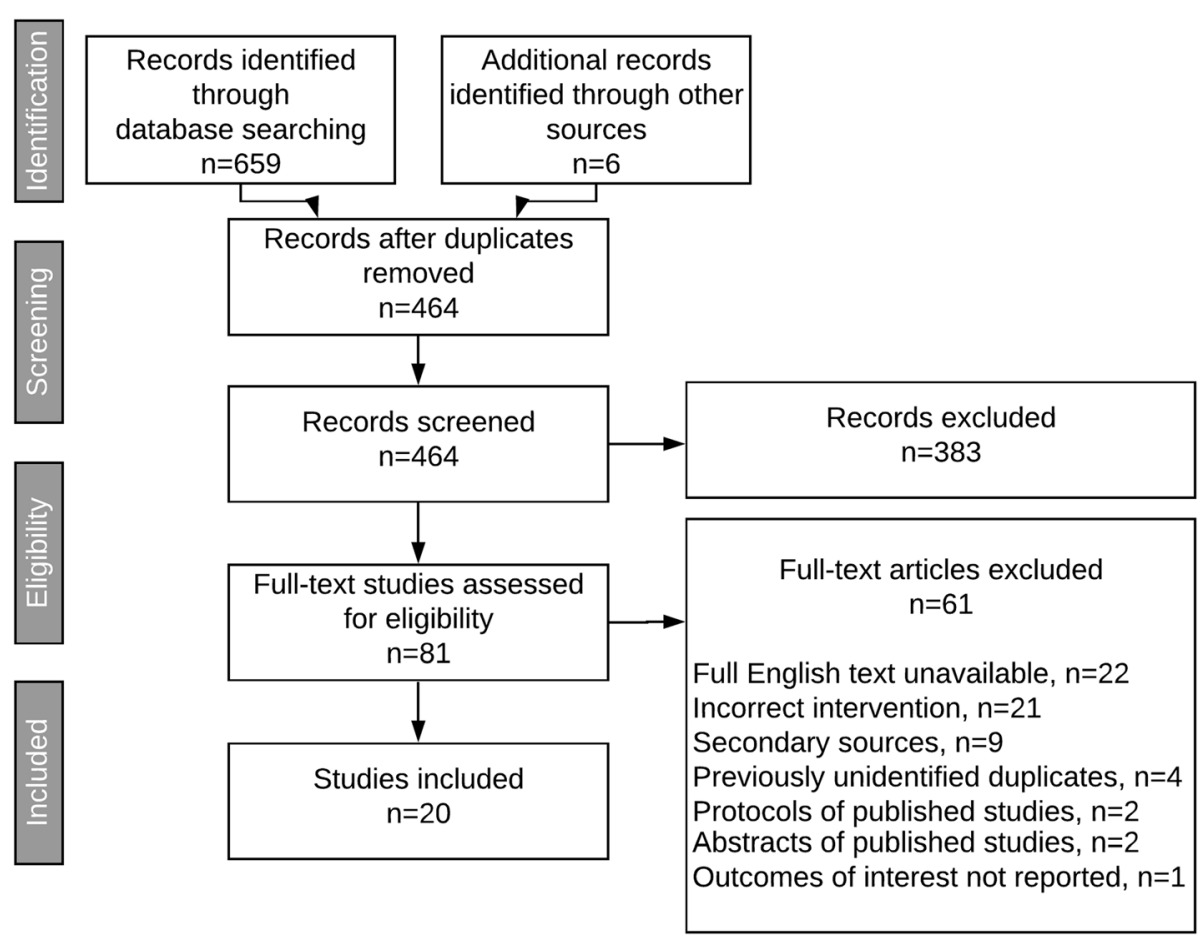

Fig. 1 PRISMA flow diagram

$21,33,35,36,42,43]$, hypertensive disorders of pregnancy $(n=1)$ [38], and overweight or obesity $(n=1)$ [39].

Study settings and data sources included hospitals/tertiary care centers $(n=10)[13,20,21,35-38,40,41,47]$, outpatient clinics $(n=4)$ [33, 34, 42, 43], online surveys $(n=2)[24,39]$, and private 'lying in' wards $(n=3)$ [4446]. One study did not provide the details of the study setting [16].

The timing of aBME varied across studies, with the majority of participants expressing at, or after, $37(n=6)$ $[16,34,37,38,40,41]$ or $36(n=5)[13,20,21,33,43]$ weeks' gestation. Less frequently, studies included women expressing at, or after, $20(n=1)$ weeks' gestation [46], or between 32 and $36(n=4)$ [36, 39, 42, 44] weeks' gestation. Brown et al. implemented aBME 3 weeks prior to each mother's expected date of delivery [47], and Waller, published in 1946, recommended the intervention in the last 3 months of pregnancy [45]. Two studies did not specify the timing of aBME [24, 35].

A concept map of the maternal and newborn outcomes assessed in the included studies is provided in Fig. 2. Maternal outcomes were categorized by those specific to the aBME practice, those pertaining to breastfeeding, and those related to downstream maternal health.

Eleven studies (55.0\%) collected data directly related to the aBME practice $[13,21,24,34,36,37,39,42,43,45$, 47]. These studies reported on the adoption of aBME
$[34,39]$, prior knowledge of aBME [24, 39], the setting and time of implementation [13], the duration and frequency of expressing episodes [13, 21, 37, 47], and the collection of colostrum (including volume collected and use of colostrum in hospital) [13, 21, 34, 36, 37, 42, 43].

Eleven studies $(55.0 \%)$ reported on maternal health outcomes among women who practiced aBME [13, 20, 21, 37, 38, 40, 41, 43, 44, 46, 47]. These outcomes included maternal blood glucose levels after aBME episodes [13, 21, 43], obstetrical complications [37], risk of engorgement and nipple injury with antenatal expression [45], onset of labour [20, 21], mode of delivery $[20,21,37,40,41]$, breast problems during breastfeeding (cracked nipples, mastitis, formation of a breast abscess, breast engorgement, nipple pain) [20, 44, 46, 47], and postpartum maternal admission to the ICU [38].

Seventeen studies $(85.0 \%)$ provided data on breastfeeding outcomes which ranged from those immediately after delivery to those at 6 months postpartum $[13,16$, 20, 21, 33, 34, 36-38, 40-47]. Breastfeeding outcomes were primarily related to newborn feeding sources (breastmilk and/or infant formula supplementation) at various times postpartum. Reported breastfeeding outcomes included perceived timing of onset of lactogenesis II $[21,38,43]$, time to full lactation $[16,40,41]$, initiation of breastfeeding and duration [20, 34, 41], source of and time to first feed [38, 42], receipt of infant 
Table 1 Study characteristics $(n=20)$

\begin{tabular}{|c|c|c|c|c|c|c|}
\hline $\begin{array}{l}\text { Author (year } \\
\text { of } \\
\text { publication), } \\
\text { Country of } \\
\text { origin }\end{array}$ & Study objective(s) & Study design & Study setting & $\begin{array}{l}\text { Sample } \\
\text { size }\end{array}$ & $\begin{array}{l}\text { Study } \\
\text { population }\end{array}$ & $\begin{array}{l}\text { Timing of } \\
\text { aBME }\end{array}$ \\
\hline $\begin{array}{l}\text { Blaikley et al. } \\
\text { (1953) [44] } \\
\text { United } \\
\text { Kingdom }\end{array}$ & $\begin{array}{l}\text { Breast-feeding: factors affecting success } \\
\text { A report of a trial of the Woolwich } \\
\text { methods in a group of primiparae. }\end{array}$ & $\begin{array}{l}\text { Interventional } \\
\text { study }\end{array}$ & Hospital lying-in ward & $n=222$ & $\begin{array}{l}\text { Pregnant } \\
\text { women }\end{array}$ & $\begin{array}{l}\text { After } 32- \\
33 \text { weeks' } \\
\text { gestation }\end{array}$ \\
\hline $\begin{array}{l}\text { Brisbane et al. } \\
\text { (2015) [34] } \\
\text { Australia }\end{array}$ & $\begin{array}{l}\text { To discuss the qualitative outcomes of } \\
\text { women who attended a prenatal care } \\
\text { clinic at } 37 \text { weeks' gestation which } \\
\text { supports the antenatal expression of } \\
\text { colostrum. }\end{array}$ & $\begin{array}{l}\text { Descriptive study - } \\
\text { Qualitative study } \\
\text { and/or survey }\end{array}$ & Antenatal breastfeeding clinic & $n=57$ & $\begin{array}{l}\text { Pregnant } \\
\text { women }\end{array}$ & $\begin{array}{l}\text { After } 37 \\
\text { weeks' } \\
\text { gestation }\end{array}$ \\
\hline $\begin{array}{l}\text { Brown et al. } \\
\text { (1975) [47] } \\
\text { United States }\end{array}$ & $\begin{array}{l}\text { Preparation of the breast for } \\
\text { breastfeeding. }\end{array}$ & $\begin{array}{l}\text { Interventional } \\
\text { study - } \\
\text { randomized } \\
\text { prospective cohort }\end{array}$ & Hospital in Colorado & $n=57$ & $\begin{array}{l}\text { Pregnant } \\
\text { women }\end{array}$ & $\begin{array}{l}3 \text { weeks } \\
\text { prior to } \\
\text { expected } \\
\text { delivery }\end{array}$ \\
\hline $\begin{array}{l}\text { Casey et al. } \\
\text { (2019) [36] } \\
\text { Australia }\end{array}$ & $\begin{array}{l}\text { To compare rates of neonatal } \\
\text { hypoglycaemia in babies born to } \\
\text { mothers who express and store } \\
\text { antenatal colostrum to babies born to } \\
\text { mothers who do not. }\end{array}$ & $\begin{array}{l}\text { Observational } \\
\text { study - } \\
\text { Retrospective } \\
\text { cohort }\end{array}$ & Regional public hospital & $n=303$ & $\begin{array}{l}\text { Pregnant } \\
\text { women with } \\
\text { diabetes }\end{array}$ & $\begin{array}{l}\text { Between } \\
34 \text { and } 36 \\
\text { weeks' } \\
\text { gestation }\end{array}$ \\
\hline $\begin{array}{l}\text { Casey et al. } \\
\text { (2019) [35] } \\
\text { Australia }\end{array}$ & $\begin{array}{l}\text { To explore the perspectives and } \\
\text { experiences of women who have had } \\
\text { diabetes in pregnancy and were } \\
\text { encouraged to collect and store } \\
\text { colostrum in the antenatal period. }\end{array}$ & $\begin{array}{l}\text { Descriptive study - } \\
\text { Qualitative study } \\
\text { and/or survey }\end{array}$ & Regional public hospital & $n=6$ & $\begin{array}{l}\text { Pregnant } \\
\text { women with } \\
\text { diabetes }\end{array}$ & $\begin{array}{l}\text { Not } \\
\text { defined }\end{array}$ \\
\hline $\begin{array}{l}\text { Clay (2005) } \\
\text { [43] United } \\
\text { Kingdom }\end{array}$ & $\begin{array}{l}\text { To provide an example of a } \\
\text { collaborative partnership approach } \\
\text { between a multidisciplinary team in a } \\
\text { joint antenatal diabetes clinic and a }\end{array}$ & $\begin{array}{l}\text { Descriptive study - } \\
\text { Case study }\end{array}$ & Antenatal diabetes clinic & $n=1$ & $\begin{array}{l}\text { Pregnant } \\
\text { woman with } \\
\text { type } 1 \\
\text { diabetes }\end{array}$ & $\begin{array}{l}\text { After } 36 \\
\text { weeks' } \\
\text { gestation }\end{array}$ \\
\hline
\end{tabular}
mother with type 1 diabetes to help her experience the harvesting of colostrum in the antenatal period and enable a positive breast-feeding outcome for her newborn daughter.

Demirci et al. To report on maternal experiences and (2018) [38] United States

Demirci et al. (2019) [37] United States

Fair et al. (2018) [39] United Kingdom breastfeeding outcomes in mothers with a hypertensive disorder of pregnancy who engaged in aBME.

Forster et al. To determine the feasibility and begin (2011) [13] Australia

Forster et al. (2017) [21] Australia

IngelmanSundberg (1958) [46] Sweden (2016) [40]
To examine the experiences of firsttime mothers in the United States who participated in a pilot study of aBME.

To assess women's knowledge, practices, and opinions of aBME as well as any differences within the overweight and obese subgroups. assessing the safety and efficacy of conducting a randomised control trial to evaluate antenatal breastmilk expression in mothers with diabetes.

To determine the safety and efficacy of aBME in women with diabetes in pregnancy.

To study the advantages of antenatal colostrum in pregnant women.

To study the effect of aBME at term pregnancy and subsequent effect on nipple message and expression of
Descriptive study Case series

Hospital-b

Descriptive study -

Qualitative study and/or survey

Descriptive study Qualitative study and/or survey

Interventional study - Pilot study hospital

Hospital-based midwife practice

Online recruitment through a maternity service user and Facebook parenting group

Public, tertiary, women's

Multi-center study across six hospitals

study -

Randomised controlled trial

Observational study - Prospective cohort

Interventional Tertiary care hospital study

\section{$n=4 \quad$ Pregnant $\quad$ Beginning women with 'around' hypertension 37 weeks' gestation \\ $n=19 \quad$ Pregnant After 37 women weeks' gestation}

$n=688$ Women who Between are pregnant 34 and 36 or who have weeks' given birth gestation

$n=43$ Pregnant After 36 women with weeks' diabetes gestation

$\begin{array}{lll}n=632 & \begin{array}{l}\text { Pregnant } \\ \text { women with } \\ \text { diabetes }\end{array} & \begin{array}{l}\text { After } 36 \\ \text { weeks' } \\ \text { gestation }\end{array} \\ n=656 & \begin{array}{l}\text { Pregnant } \\ \text { women }\end{array} & \begin{array}{l}\text { After 20 } \\ \text { weeks' } \\ \text { gestation }\end{array}\end{array}$

$n=200 \quad$ Pregnant After 37 weeks' 
Table 1 Study characteristics $(n=20)$ (Continued)

\begin{tabular}{|c|c|c|c|c|c|c|}
\hline $\begin{array}{l}\text { Author (year } \\
\text { of } \\
\text { publication), } \\
\text { Country of } \\
\text { origin } \\
\end{array}$ & Study objective(s) & Study design & Study setting & $\begin{array}{l}\text { Sample } \\
\text { size }\end{array}$ & $\begin{array}{l}\text { Study } \\
\text { population }\end{array}$ & $\begin{array}{l}\text { Timing of } \\
\text { aBME }\end{array}$ \\
\hline India & postnatal lactation performance. & & & & & gestation \\
\hline $\begin{array}{l}\text { O'Sullivan } \\
\text { et al. (2019) } \\
\text { [24] Australia }\end{array}$ & $\begin{array}{l}\text { To determine whether an online } \\
\text { instructional video can improve } \\
\text { knowledge and confidence around the } \\
\text { antenatal expression of colostrum. }\end{array}$ & $\begin{array}{l}\text { Interventional } \\
\text { study - before/after } \\
\text { comparison }\end{array}$ & $\begin{array}{l}\text { Online recruitment through } \\
\text { social media via university and } \\
\text { research institutions, infant and } \\
\text { mother organizations, and } \\
\text { personal contacts }\end{array}$ & $n=95$ & $\begin{array}{l}\text { Pregnant } \\
\text { women }\end{array}$ & $\begin{array}{l}\text { Not } \\
\text { defined }\end{array}$ \\
\hline $\begin{array}{l}\text { Rietveld } \\
\text { (2011) [42] } \\
\text { New Zealand }\end{array}$ & $\begin{array}{l}\text { To determine if pregnant woman with } \\
\text { Type 1, Type } 2 \text { or gestational diabetes } \\
\text { mellitus can effectively achieve } \\
\text { antenatal colostrum harvesting and } \\
\text { banking. } \\
\text { To assess the feasibility of mothers and } \\
\text { core midwifery staff using banked } \\
\text { colostrum as part of the care of } \\
\text { hypoglycaemic babies in the hospital } \\
\text { setting. }\end{array}$ & $\begin{array}{l}\text { Interventional } \\
\text { study - Pilot study }\end{array}$ & $\begin{array}{l}\text { Antenatal diabetic outpatient } \\
\text { clinic }\end{array}$ & $n=10$ & $\begin{array}{l}\text { Pregnant } \\
\text { women with } \\
\text { diabetes }\end{array}$ & $\begin{array}{l}\text { After } 34 \\
\text { weeks' } \\
\text { gestation }\end{array}$ \\
\hline $\begin{array}{l}\text { Singh et al. } \\
\text { (2009) [16] } \\
\text { India }\end{array}$ & $\begin{array}{l}\text { To study the effect of aBME at term in } \\
\text { reducing breast feeding failure } \\
\text { compared to conventional method of } \\
\text { breastfeeding initiation. }\end{array}$ & $\begin{array}{l}\text { Interventional } \\
\text { study }\end{array}$ & Not stated & $n=180$ & $\begin{array}{l}\text { Pregnant } \\
\text { women }\end{array}$ & $\begin{array}{l}\text { After } 37 \\
\text { weeks' } \\
\text { gestation }\end{array}$ \\
\hline $\begin{array}{l}\text { Soltani et al. } \\
\text { (2012) [20] } \\
\text { United } \\
\text { Kingdom }\end{array}$ & $\begin{array}{l}\text { To examine the adoption of aBME as } \\
\text { an intervention and investigate its } \\
\text { relationship to birth outcomes among } \\
\text { mothers with diabetes. }\end{array}$ & $\begin{array}{l}\text { Observational } \\
\text { study - } \\
\text { Retrospective } \\
\text { cohort }\end{array}$ & National health service trust & $n=85$ & $\begin{array}{l}\text { Pregnant } \\
\text { women with } \\
\text { diabetes }\end{array}$ & $\begin{array}{l}\text { After } 36 \\
\text { weeks' } \\
\text { gestation }\end{array}$ \\
\hline $\begin{array}{l}\text { Uikey et al. } \\
\text { (2017) [41] } \\
\text { India }\end{array}$ & $\begin{array}{l}\text { To study the effect of aBME in } \\
\text { improving lactational performance. }\end{array}$ & $\begin{array}{l}\text { Interventional } \\
\text { study }\end{array}$ & Tertiary care center & $n=200$ & $\begin{array}{l}\text { Pregnant } \\
\text { women }\end{array}$ & $\begin{array}{l}\text { After } 37 \\
\text { weeks' } \\
\text { gestation }\end{array}$ \\
\hline $\begin{array}{l}\text { Waller (1946) } \\
\text { [45] United } \\
\text { Kingdom }\end{array}$ & $\begin{array}{l}\text { The early failure of breastfeeding: A } \\
\text { clinical study of its cause and their } \\
\text { prevention. }\end{array}$ & $\begin{array}{l}\text { Interventional } \\
\text { study }\end{array}$ & Hospital lying-in ward & $n=200$ & $\begin{array}{l}\text { Pregnant } \\
\text { women }\end{array}$ & $\begin{array}{l}\text { Last } 3 \\
\text { months of } \\
\text { pregnancy }\end{array}$ \\
\hline $\begin{array}{l}\text { Weinel et al. } \\
\text { (2019) [33] } \\
\text { Australia }\end{array}$ & $\begin{array}{l}\text { To support mothers who had pre- } \\
\text { existing or gestational diabetes, and } \\
\text { who were on more than } 20 \text { units of in- } \\
\text { sulin per day, to express colostrum in } \\
\text { the antenatal period at } 36 \text { weeks' gesta- } \\
\text { tion and to promote breastfeeding. }\end{array}$ & $\begin{array}{l}\text { Quality } \\
\text { improvement study }\end{array}$ & $\begin{array}{l}\text { Diabetic antenatal care } \\
\text { education clinic }\end{array}$ & $n=207$ & $\begin{array}{l}\text { Pregnant } \\
\text { women with } \\
\text { diabetes }\end{array}$ & $\begin{array}{l}\text { After } 36 \\
\text { weeks' } \\
\text { gestation }\end{array}$ \\
\hline
\end{tabular}

formula and/or breastmilk at various time points [13, 21, $36,44,45$ ], feeding type in hospital including the use of antenatally expressed milk [38], newborn LATCH scores [38], breastfeeding status at various time points postpartum [33, 37, 38, 42, 44, 46], use of an electric pump [37], and reasons for breastfeeding cessation [34]. One study measured the total amount of breastmilk suckled and expressed 7 days after delivery [46], and another reported on the intensity of sucking action of the newborn, the number of minutes newborn sucked at each breast, and the length of time since the last feed [47].

Ten studies $(50.0 \%)$ collected data on fetuses or newborns of mothers who practiced aBME [13, 20, 21, 3638, 42-44, 47]. Assessed outcomes included metrics of fetal wellbeing during aBME [21], gestational age at birth [20, 21, 36, 37, 42], birthweight [20, 21, 37, 47], Apgar scores $[20,21,36]$, blood glucose measurements (time to first measure, glucose levels at various time points) [13, 36], neonatal hypoglycemia [36, 42, 43], whether the newborn received intravenous glucose [13, 36], admission to NICU/SCN/SCBU (reason for admission, time spent) $[13,20,21,36-38]$, receipt of infant formula (various time points) [36-38, 42, 43], and other neonatal complications (jaundice, respiratory distress, sepsis, neonatal resuscitation, newborn death) [36, 37, 44].

Among all reported outcomes, the most frequently reported were breastfeeding status (at time of study, in first $48 \mathrm{~h}$ of life, at discharge, at 1-2 weeks, 4-8 weeks, 3 months, 4 months, and 6 months postpartum), mode of delivery (vaginal/cesarean), volume of colostrum collected, and newborn blood glucose measurements (time to first measure, glucose levels at 3, 12 , and $24 \mathrm{~h}$ postpartum, or at the first, second, and third measurement). 


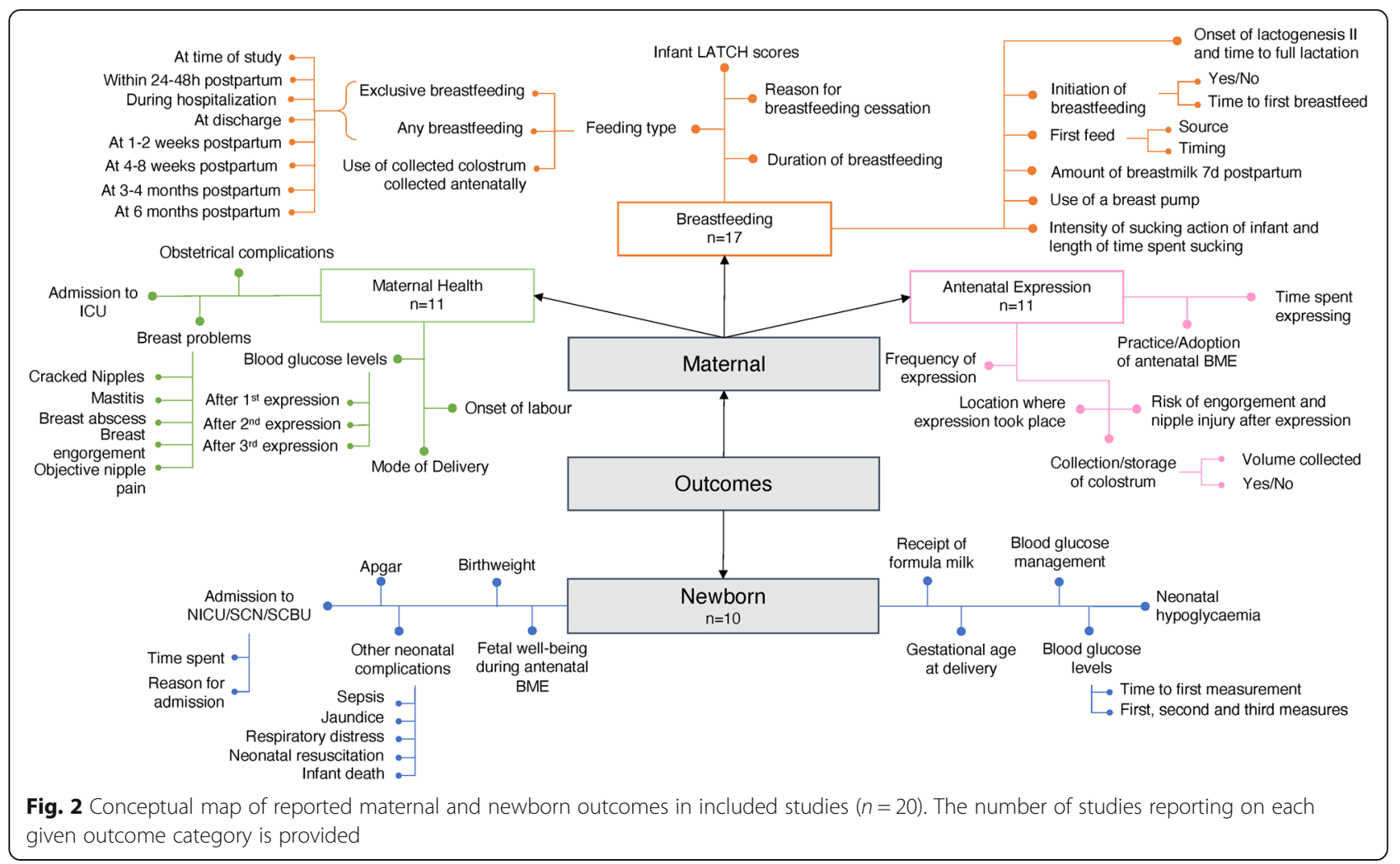

Ten studies $(50.0 \%)$ provided evidence on maternal knowledge, attitudes, and experiences related to aBME $[13,24,34,35,37-40,42,47]$. Data were obtained through patient diary documentation [13], structured or semi-structured postpartum interviews [34, 35, 37, 38], questionnaires [13, 24, 34, 39, 47], and online surveys (fixed and free text responses) [38, 42]. One study did not specify how they obtained data on maternal experiences [40]. Broadly categorized by theme, these studies collected information regarding participants' sense of confidence and mastery as a result of aBME; senses of security and altruism attributed to aBME; receptivity to aBME resources or learning how to express; perceived impacts of aBME on maternal and newborn health; challenges related to attempting or practicing aBME; and the physical symptoms experienced as a consequence of aBME. Themes specific to maternal knowledge, attitudes, and experiences captured by included studies are summarized in Fig. 3.

\begin{tabular}{|c|c|c|}
\hline Confidence and Mastery & $\begin{array}{l}\text { Perceived impact } \\
\text { of antenatal BME }\end{array}$ & Physical symptoms \\
\hline $\begin{array}{l}\text { - Familiarity and satisfaction with the } \\
\text { process } \\
\text { - Self management and ownership } \\
\text { - Building fortitude for motherhood }\end{array}$ & $\begin{array}{l}\text { - Attributed to milk let down, early } \\
\text { availability of milk for breastfeeding } \\
\text { - Beneficial for breastfeeding outcomes } \\
\text { - Likelihood of expressing antenatally again } \\
\text { if it was shown to be beneficial }\end{array}$ & $\begin{array}{l}\text { - Discomfort or pain } \\
\text { - Feeling of breast fullness before and after }\end{array}$ \\
\hline Security and Altruism & Learning and Resources & Challenges \\
\hline $\begin{array}{l}\text { Feeling of preparedness with collected } \\
\text { colostrum ready for baby } \\
\text { - Feeling good for having done something } \\
\text { for the baby }\end{array}$ & $\begin{array}{l}\text { - General breastfeeding education } \\
\text { - Feedback on antenatal BME education } \\
\text { program } \\
\text { - Learning how to express } \\
\text { - Feedback on educational videos } \\
\text { - Likelihood of suggesting antenatal BME } \\
\text { after watching an educational video }\end{array}$ & $\begin{array}{l}\text { - Internal pressure to succeed } \\
\text { - Weariness of medicalization } \\
\text { - Anxiety about insufficient colostrum } \\
\text { - Frustration with waste of colostrum } \\
\text { - Futility of antenatal BME } \\
\text { - Time or energy burden } \\
\text { - Embarrassment or awkwardness } \\
\text { - Lack of privacy }\end{array}$ \\
\hline
\end{tabular}


The results of our critical appraisal are summarized in Table 2. Three studies (15\%) did not meet the screening question criteria, indicating that they may not be empirical studies that could robustly be evaluated by the MMAT $[33,43,46]$. Five studies $(25 \%)$ met $1 / 2$ of the screening criteria questions [13, 38,44, 45, 47], and 12 studies $(60 \%)$ fulfilled both screening question criteria $[16,20,21,24,34-37,39-42]$. Significant methodological weaknesses were evident in the majority of the studies reviewed. On average, the included studies successfully fulfilled $2.15 / 5$ of the MMAT methodology appraisal criteria. Thirty-five percent $(n=7)$ fulfilled $>2 / 5$ methodological appraisal questions $[20,21,34,35,37-$ 39]; four were qualitative studies [41, 42, 44, 45], one was a quantitative descriptive study [38], one was a quantitative RCT [21], and one was a quantitative nonrandomized study [20]. Additionally, six of these seven studies $(85.7 \%)$ were published in the last 5 years $(2015-$ 2019) [21,34, 35, 37-39]. Only two studies fulfilled all five of the methodological quality appraisal criteria, both of which are qualitative in nature [35, 37]. Although there was only one registered RCT among the included studies [21], four other studies were evaluated as quantitative RCTs due to mention of a randomization process described in their methodology [16, 40, 41, 47]. A complete summary of all screening and methodology questions, results, and comments supporting the authors' decisions are provided in the Additional file 3.

Studies were commonly limited by unclear research questions or unclear descriptions of their intervention/outcome measures. Consequently, in many cases, we were unable to confirm whether findings appropriately addressed the indicated research question and were unable to effectively compare the findings across studies. A summary of methodological limitations identified is provided in Table 3.

\section{Discussion}

Our findings demonstrate a rising interest in the safety, efficacy, and acceptability of aBME. Of the 20 studies identified by our search strategy, the majority were published in the last 5 years and originated from Australia. The current evidence surrounding aBME includes

Table 2 Summary of Mixed Methods Appraisal Tool (MMAT) [32] results evaluating quality of included studies $(n=20)$

\begin{tabular}{|c|c|c|c|}
\hline $\begin{array}{l}\text { Author (year of } \\
\text { publication) }\end{array}$ & $\begin{array}{l}\text { Screening questions (number of } \\
\text { 'yes') }\end{array}$ & MMAT study design & $\begin{array}{l}\text { Methodological quality questions (number } \\
\text { of 'yes') }\end{array}$ \\
\hline Blaikley et al. (1953) [44] & $1 / 2$ & Quantitative non-randomized & $2 / 5$ \\
\hline Brisbane et al. (2015) [34] & $2 / 2$ & Qualitative study & $3 / 5$ \\
\hline Brown et al. (1975) [47] & $1 / 2$ & $\begin{array}{l}\text { Quantitative randomized control } \\
\text { trial }\end{array}$ & $2 / 5$ \\
\hline Casey et al. (2019) [36] & $2 / 2$ & Quantitative non-randomized & $2 / 5$ \\
\hline Casey et al. (2019) [35] & $2 / 2$ & Qualitative study & $5 / 5$ \\
\hline Clay (2005) [43] & $0 / 2$ & Qualitative study & $0 / 5$ \\
\hline Demirci et al. (2018) [38] & $1 / 2$ & Quantitative descriptive & $4 / 5$ \\
\hline Demirci et al. (2019) [37] & $2 / 2$ & Qualitative study & $5 / 5$ \\
\hline Fair et al. (2018) [39] & $2 / 2$ & Qualitative study & $3 / 5$ \\
\hline Forster et al. (2011) [13] & $1 / 2$ & Quantitative non-randomized & $2 / 5$ \\
\hline Forster et al. (2017) [21] & $2 / 2$ & $\begin{array}{l}\text { Quantitative randomized control } \\
\text { trial }\end{array}$ & $3 / 5$ \\
\hline $\begin{array}{l}\text { Ingelman-Sundberg (1958) } \\
\text { [46] }\end{array}$ & $0 / 2$ & Quantitative non-randomized & $0 / 5$ \\
\hline Lamba et al. (2016) [40] & $2 / 2$ & $\begin{array}{l}\text { Quantitative randomized } \\
\text { controlled trial }\end{array}$ & $1 / 5$ \\
\hline O'Sullivan et al. (2019) [24] & $2 / 2$ & Qualitative study & $2 / 5$ \\
\hline Rietveld (2011) [42] & $2 / 2$ & Mixed methods & $2 / 5$ \\
\hline Singh et al. (2009) [16] & $2 / 2$ & $\begin{array}{l}\text { Quantitative randomized control } \\
\text { trial }\end{array}$ & $1 / 5$ \\
\hline Soltani et al. (2012) [20] & $2 / 2$ & Quantitative non-randomized & $3 / 5$ \\
\hline Uikey et al. (2017) [41] & $2 / 2$ & $\begin{array}{l}\text { Quantitative randomized } \\
\text { controlled trial }\end{array}$ & $1 / 5$ \\
\hline Waller (1946) [45] & $1 / 2$ & Quantitative non-randomized & $1 / 5$ \\
\hline Weinel et al. (2019) [33] & $0 / 2$ & Quantitative descriptive & $1 / 5$ \\
\hline
\end{tabular}


largely observational studies with low-risk mothers who were encouraged to express around 36 weeks' gestation. Research questions, interventions, and outcomes of interest varied widely; however, breastfeeding outcomes were high yield $(n=17)$. A critical appraisal of included studies highlighted limitations in participant sampling, data collection, and reporting, suggesting research is warranted to rule out potential sources of bias and validate results. We identified only one RCT evaluating outcomes of aBME [21], however Demirci and colleagues registered a RCT in February of 2020 that will be assessing the effect of aBME on multiple breastfeeding outcomes in non-diabetic mothers with a body mass index $>25 \mathrm{~kg} / \mathrm{m}^{2}$ [48].

Antenatal BME may be recommended to pregnant women for a wide range of reasons, including to promote lactogenesis, enhance breastfeeding success, and/or support collection of colostrum for postpartum use [13-

Table 3 Common methodological flaws of included studies $(n=20)$

- Research question or study outcomes related to aBME not well-defined

- Incomplete description of study procedures preventing reproducibility (target population, inclusion/exclusion criteria, exposures/interventions, outcomes)

- Limited description of the aBME protocol and supports provided to study participants

- Limited information on the collection of colostrum from aBME, its use postpartum, and impact on the study outcomes

- Inadequate or incomplete measures of lactational and breastfeeding outcomes

- Limited information on participant retention and loss-to-follow-up, and comparative data between the final study sample and nonrespondents/those lost during the course of the study

- Lack of comprehensive baseline data on study participants

- Limited collection or presentation of data on patterns of exclusive and mixed breastfeeding, pumping and infant formula supplementation, and little information on the reasons for infant formula supplementation (in-hospital or after discharge)

- For randomized trials, limited description of randomization, allocation and blinding procedures

- For quantitative studies, lack of pre-sample size calculations or power considerations

- For quantitative studies, inappropriate matching of comparisons groups, or insufficient description of the matching criteria

- For quantitative studies, not accounting for, or reporting on, participant compliance to the study intervention

- For qualitative studies, limited information on the validity of the data collection tools, theoretical frameworks applied to guide study design or data analysis

- For mixed methods studies, rationale for using a mixed-methods design was infrequently provided and there was limited integration of qualitative and quantitative findings

- Not accounting for confounding variables or mediating factors (e.g. parity, obesity, breastfeeding history in previous pregnancies, socioeconomic status and breastfeeding supports received)
15]. This was reflected in the studies included in this scoping review where the research questions were varied, instructions on the timing and method of aBME were inconsistent, and the outcomes of interest were often ambiguous. All of the studies that provided details on the method of breastmilk expression indicated hand expression, however the specific manner in which milk was expressed (i.e. nipple massage, nipple rolling, breast massage) varied and was often not detailed. The most effective and efficient method of aBME is unclear. Moreover, variability in the frequency and duration of expression was noted. Forster et al. recommended expressing twice daily for $10 \mathrm{~min}$ until hospital admission or delivery $[13,21]$. In contrast, Lamba and colleagues recommended expressing at least once daily for $5 \mathrm{~min}$ [40], Weinel et al. recommended expressing up to $5 \mathrm{~min}$ per breast daily or twice daily [33], and Clay et al. recommended expressing three times a day without specifying the length of each expression [43]. The gestational age at which aBME was initiated also varied. Eleven studies recommended expressing between 36 and 37 weeks' gestation, four studies recommended expressing between 32 and 36 weeks' gestation, and the remaining recommended expressing earlier or did not state their time of initiation. If the goal is to determine the safety and efficacy of aBME, consensus on the appropriate timing of aBME initiation is required in order to standardize the intervention. Importantly, women with diabetes tend to be induced between 38 and 40 weeks' gestation, or before if they have poor glycemic control $[49,50]$. This should be taken into consideration when establishing a starting point for aBME in this specific population.

The highest-quality study by nature of its RCT design was conducted by Forster et al. [21]. This study included 635 women with gestational or pre-existing diabetes with a singleton, low risk pregnancy. Participants were randomized into an aBME group or a control group who received standard care provided at their local tertiary care facility. The primary outcomes of interest were newborn admission to the NICU and gestational age at birth, which did not differ between the expressing and control groups, repealing the preconceived risks of elevated NICU admission and lower gestational age associated with aBME. This study also reported moderate evidence that infants of women who expressed antenatally were more likely to be exclusively breastfed in the first day of life and during their initial hospital stay (from birth to discharge, or 7 days of age if they had an extended hospital stay). Although data on participant adherence to their assigned intervention were not provided, the research question was clear, the randomization strategy was well defined, the comparison groups were appropriately matched, and the outcome assessors were masked to the allocation of participants to 
the intervention arms. This study provides a useful framework for the development of protocols for future research. These include the commencement of aBME at 36 weeks' gestation in mothers with diabetes, assessment of the duration and frequency of antenatal expressing episodes, collection and measurement of colostrum, and lastly, tracking the administration of colostrum to newborns. Where there are many maternal and newborn outcomes related to aBME that may be explored, establishing clear research questions will be essential to advancing knowledge on the safety, efficacy and acceptability of the practice and its effect on measured outcomes.

A multitude of maternal and newborn outcomes following aBME were investigated across the included studies. The most commonly reported outcomes focused on the collection and use of colostrum, breastfeeding status and success at various time points, and outcomes related to newborn health and safety. Documentation of the volumes of colostrum that mothers express, and the amount administered to newborns is important to provide insight into the impact of using expressed breastmilk on newborn health versus with standardized newborn hypoglycemia management protocols which can include enteral feeds of breastmilk, breastmilk substitutes, intrabuccal dextrose gel, or intravenous glucose to stabilize newborn blood glucose levels [51]. Outcomes related to breastfeeding success and status were common among the studies included in this scoping review, however breastfeeding success was often not defined and duration of participant follow-up varied greatly. Three studies reported on time to establishing full lactation $[16,40,41]$, and one reported standardized LATCH scores [38]. Definitions used to ascertain 'time to full lactation' were unclear however, and likely incongruent with accepted definitions [52]. Although many measures can be used to evaluate breastfeeding success, there is currently no single accepted measurement tool to assess this outcome [53]. Lastly, newborn health and safety outcomes were of particular interest due to recent concerns around preterm birth and increased NICU admission following aBME. Forster et al. evaluated these outcomes in their RCT and did not find any evidence that aBME was unsafe for newborns [21].

Evaluating the receptivity of women to aBME, their feedback on aBME resources and supports, as well as their perceptions and experiences with aBME are essential for informing the reasonable implementation of aBME research studies, clinical recommendations and programming. Among the studies included in this review, data on maternal experiences were captured mostly by interviews (semi-structured and structured) and questionnaires. Findings demonstrated that mothers had a generally positive outlook on aBME. Mothers reported feeling a sense of ownership and confidence with breastfeeding after practicing aBME, however mothers also complained of discomfort and frustration with the process.

Strengths of this scoping review include the use of established frameworks to ensure the unbiased identification and appraisal of relevant studies. The scoping review methodology allowed us to apply a broad research question and iterative search strategy to conduct a comprehensive synthesis of the current literature on aBME. Our methodology was significantly strengthened through our incorporation of a critical appraisal and clinical consultation which allowed us to provide new perspectives to this topic. This review was limited by the fact that we could only include articles published in English. We may also have excluded relevant studies because we were unable to retrieve the full texts at the time of data collection.

\section{Conclusions}

This review demonstrates a lack of high-quality evidence on the effects of aBME on maternal and newborn outcomes. Published studies on the maternal and newborn outcomes of aBME vary widely in their hypotheses and objectives, target populations, interventions, and outcomes of interest, thus hampering comparison across studies. Future work should focus on clear hypothesis driven approaches and provide published or registered protocols outlining the method of breast expression, the timing of the intervention, the storage and use of the colostrum collected, and infant formula supplementation for breastfed infants. Lastly, having well-described populations with appropriate comparison groups is imperative to minimize confounding variables and mediating factors. Given that aBME is thought to be particularly beneficial to pregnant women with diabetes, future studies should consider primarily evaluating outcomes in this population. For researchers conducting trials on mothers with diabetes, willingness to participate and satisfaction with the intervention should be considered as these women often experience other unique burdens in pregnancy such as visits with health specialists and frequent blood glucose monitoring. Our findings provide insight into the many outcomes and experiences that can be considered in the evaluation of aBME and may be useful for informing the development and implementation of future research.

\footnotetext{
Abbreviations

aBME: Antenatal breastmilk expression; CINAHL: Cumulated Index to Nursing and Allied Health Literature; EBSCOHost: Online research platform; EThOS: ETheses Online Services; ICU: Intensive care unit; LATCH scores: Latch, Audible swallowing, Type of nipple, Comfort, Hold; MMAT: Mixed Methods Appraisal Tool; NICU: Neonatal intensive care unit; OVID: Ovid is a platform that hosts databases; MEDLINE: Is a database that is hosted on the OVID platform; RCT: Randomized controlled trial; SCBU: Special care baby unit; SCN: Special care nursery
} 


\section{Supplementary Information}

The online version contains supplementary material available at https://doi. org/10.1186/s13006-021-00371-7.

Additional file 1. Literature Search Strategy.

Additional file 2. Data collection form template.

Additional file 3. Detailed critical appraisal of included studies.

\section{Acknowledgements}

The authors would like to thank Ms. Karine Fournier for her assistance in developing the search strategy. The authors would also like to thank the OMNI Research Group at the Ottawa Hospital Research Institute for their continued support throughout the development of this study.

\section{Authors' contributions}

All authors IFB, MSQM, SD, EJK, DEC contributed to the analysis of the results, drafting and editing of the manuscript, and approval of the final version and take responsibility for the integrity of the data and the accuracy of the data analysis. DEC as PI is guarantor and corresponding author.

\section{Funding}

This research is being supported by a Canadian Institutes for Health Research Foundation Grant [FDN 148438]. The funding agency is not involved in study design or analysis and interpretation of data. The agency was not involved in the development of this protocol or in the decision to submit it for publication. This research is also supported by the University of Ottawa Faculty of Medicine Summer Studentship bursary.

\section{Availability of data and materials}

The data analyzed during this scoping review of the literature are publicly available.

\section{Declarations}

\section{Ethics approval and consent to participate}

Research ethics approval was not required due to the nature of the study methodology. The enclosed manuscript has neither been previously published nor submitted to another journal for publication.

The protocol of the manuscript was registered on the Open Science Framework [osf.io/gfp2q] and later published in BMJ open [doi: https://doi. org/10.1136/bmjopen-2019-033101]. This study was presented at the University of Ottawa Faculty of Medicine Research Day (Ottawa, 2019) and the Canadian National Perinatal Research Meet (Alberta, 2020).

\section{Consent for publication}

Not applicable.

\section{Competing interests}

The authors declare that they have no financial or other competing interests.

\section{Author details}

'OMNI Research Group, Clinical Epidemiology Program, Ottawa Hospital Research Institute, Ottawa, Canada. ${ }^{2}$ Faculty of Medicine, University of Ottawa, Ottawa, Canada. ${ }^{3}$ Division of Endocrinology and Metabolism, Department of Medicine, University of Ottawa, Ottawa, Canada. ${ }^{4}$ Diabetes, Obesity, Metabolism and Endocrinology Program, Ottawa Hospital Research Institute, Ottawa, Canada. ${ }^{5}$ Foustanellas Endocrine \& Diabetes Centre, The Ottawa Hospital, Ottawa, Canada. ${ }^{6}$ Department of Obstetrics and Gynecology, University of Ottawa, Ottawa, Canada. ${ }^{7}$ Department of Obstetrics, Gynecology \& Newborn Care, The Ottawa Hospital, General Campus, CPCR, Box 241, 501 Smyth Rd, Ottawa, ON K1H 8L6, Canada.

\section{Received: 26 October 2020 Accepted: 2 March 2021}

Published online: 12 March 2021

\section{References}

1. WHO. Protecting, promoting and supporting breastfeeding in facilities providing maternity and newborn services: World Health Organization; 2017.
2. Family-Centred Maternity and Newborn Care: National Guidelines. Ottawa: Public Health Agency of Canada; 2018. https://www.canada.ca/content/da $\mathrm{m} /$ phac-aspc/documents/services/publications/healthy-living/maternitynewborn-care-guidelines-chapter-6/maternity-newborn-care-guidelines-cha pter-6.pdf. Accessed 18 Mar 2020.

3. Nutrition for healthy term infants: recommendations from birth to six months. Can J Diet Pr Res. 2012;73. https://doi.org/10.3148/73.4.2012.204.

4. BCC BFI integrated 10 steps practice outcome indicators for hospitals and community health services. Breastfeeding Committee for Canada. 2017. http://www.breastfeedingcanada.ca/documents/Indicators-completeJune201 7.pdf. Accessed 18 Mar 2020

5. Pound CM, Unger SL, Canadian Paediatric Society, Nutrition and Gastroenterology Committee HPS. The baby-friendly initiative: protecting, promoting and supporting breastfeeding: position statement. 2020. https:// www.cps.ca/en/documents/position/baby-friendly-initiative-breastfeeding. Accessed 18 Mar 2020

6. BCC. Breastfeeding definitions and data collection periods. Ottawa; 2012

7. Maayan-Metzger A, Lubin D, Kuint J. Hypoglycemia rates in the first days of life among term infants born to diabetic mothers. Neonatology. 2009;96:805 https://doi.org/10.1159/000203337.

8. Arthur PG, Kent JC, Hartmann PE. Metabolites of lactose synthesis in milk from diabetic and nondiabetic women during lactogenesis II. J Pediatr Gastroenterol Nutr. 1994;19:100-8 https://doi.org/10.1097/00005176-1994 07000-00017.

9. De Bortoli J, Amir LH. Is onset of lactation delayed in women with diabetes in pregnancy? A systematic review. Diabet Med. 2015;33:17-24 https://doi. org/10.1111/dme.12846.

10. Chapman T, Pincombe J, Harris M. Antenatal breast expression: a critical review of the literature. Midwifery. 2013;29:203-10 https://doi.org/10.1016/j. midw.2011.12.013.

11. Fallon A, Dunne F. Breastfeeding practices that support women with diabetes to breastfeed. Diabetes Res Clin Pract. 2015;110:10-7 https://doi. org/10.1016/j.diabres.2015.07.006

12. Tozier PK. Colostrum versus formula supplementation for glucose stabilization in newborns of diabetic mothers. J Obstet Gynecol Neonatal Nurs. 2013;42:619-28 https://doi.org/10.1111/1552-6909.12260.

13. Forster DA, McEgan K, Ford R, Moorhead A, Opie G, Walker S, et al. Diabetes and antenatal milk expressing: a pilot project to inform the development of a randomised controlled trial. Midwifery. 2011;27:209-14 https://doi.org/10.1 016/j.midw.2009.05.009.

14. East CE, Dolan WJ, Forster DA. Antenatal breast milk expression by women with diabetes for improving infant outcomes. Cochrane Database Syst Rev. 2014:CD010408 https://doi.org/10.1002/14651858.CD010408.pub2.

15. Cox SG. Expressing and storing colostrum antenatally for use in the newborn period. Breastfeed Rev. 2006;14:11-6.

16. Singh $G$, Chouhan $R$, Sidhu K. Effect of antenatal expression of breast milk at term in reducing breast feeding failures. Med J Armed Forces India. 2009;65: 131-3 https://doi.org/10.1016/S0377-1237(09)80125-1.

17. Cox SG. An ethical dilemma: should recommending antenatal expressing and storing of colostrum continue? Breastfeed Rev. 2010;18:5-7 https://doi. org/10.1016/jmidw.2009.05.009.

18. Oscroft R. Antenatal expression of colostrum. Pract Midwife. 2001;4:32-5

19. Forster DA, Jacobs S, Amir LH, Davis P, Walker SP, McEgan K, et al. Safety and efficacy of antenatal milk expressing for women with diabetes in pregnancy: protocol for a randomised controlled trial. BMJ Open. 2014;4: e006571 https://doi.org/10.1136/bmjopen-2014-006571.

20. Soltani H, Scott AMS. Antenatal breast expression in women with diabetes: outcomes from a retrospective cohort study. Int Breastfeed J. 2012;7 https:// doi.org/10.1186/1746-4358-7-18.

21. Forster DA, Moorhead AM, Jacobs SE, Davis PG, Walker SP, McEgan KM, et al. Advising women with diabetes in pregnancy to express breastmilk in late pregnancy (Diabetes and Antenatal Milk Expressing [DAME]): a multicentre, unblinded, randomised controlled trial. Lancet. 2017;389:220413 https://doi.org/10.1016/S0140-6736(17)31373-9.

22. Hand expressing breast milk before your baby is born. 2013. www.healthyfa miliesbc.ca/home/articles/video-hand-expressing-breastmilk. Accessed 19 Mar 2020

23. Antenatal expression of colostrum. n.d. https://www.laleche.org.uk/antenata l-expression-of-colostrum/. Accessed 19 Mar 2020. 
24. O'Sullivan TA, Cooke J, McCafferty C, Giglia R. Online video instruction on hand expression of colostrum in pregnancy is an effective educational tool. Nutrients. 2019;11:883 https://doi.org/10.3390/nu11040883.

25. Peterson J, Pearce PF, Ferguson LA, Langford CA. Understanding scoping reviews: definition, purpose, and process. J Am Assoc Nurse Pract. 2017;29: 12-6 https://doi.org/10.1002/2327-6924.12380.

26. Foudil-Bey I, Murphy MS, Keely E, El-Chaâr D. Maternal and newborn outcomes of antenatal breastmilk expression: a scoping review protocol. Open Sci Framew. 2019. https://osf.io/gfp2q. Accessed 10 Feb 2021.

27. Foudil-Bey I, Murphy MS, Keely EJ, El-Chaâr D. Maternal and newborn outcomes of antenatal breastmilk expression: a scoping review protocol. BMJ Open. 2020;10:e033101 https://doi.org/10.1136/bmjopen-2019-033101.

28. Peters M, Godfrey C, Mclnerney P, Munn Z, Tricco A, Khalil H. Chapter 11: scoping reviews: The Joanna Briggs Institute; 2020. https://doi.org/10.46658/ JBIMES-20-12

29. Arksey H, O'Malley L. Scoping studies: towards a methodological framework. Int J Soc Res Methodol. 2005;8:19-32 https://doi.org/10.1080/1364557032 000119616.

30. Levac D, Colquhoun H, O'Brien KK. Scoping studies: advancing the methodology. Implement Sci. 2010;5:69 https://doi.org/10.1186/1748-5908 5-69.

31. Covidence systematic review software. Veritas Health Innovation. n.d. https://www.covidence.org. Accessed 21 June 2019.

32. Hong Q, Pluye P, Fabregues S, Bartlett G, Boardman F, Cargo M, et al. Mixed methods appraisal tool (MMAT) version 2018. Montreal; 2018.

33. Weinel $H$, Cusack $L$. Lessons learned from the introduction of an antenatal human milk expression clinic for women with diabetes. J Hum Lact. 2019; 35:725-8 https://doi.org/10.1177/0890334419836981.

34. Brisbane JM, Giglia RC. Experiences of expressing and storing colostrum antenatally: a qualitative study of mothers in regional Western Australia. J Child Health Care. 2015;19:206-15 https://doi.org/10.1177/1367493513503 586.

35. Casey JRR, Mogg EL, Banks J, Braniff K, Heal C. Perspectives and experiences of collecting antenatal colostrum in women who have had diabetes during pregnancy: a North Queensland semistructured interview study. BMJ Open. 2019;9:e021513 https://doi.org/10.1136/bmjopen-2018-021513.

36. Casey JRR, Banks J, Braniff K, Buettner P, Heal C. The effects of expressing antenatal colostrum in women with diabetes in pregnancy: a retrospective cohort study. Aust N Z J Obstet Gynaecol. 2019;59:811-8 https://doi.org/1 0.1111/ajo.12966.

37. Demirci JR, Glasser M, Fichner J, Caplan E, Himes KP. "It gave me so much confidence": First-time U.S. mothers' experiences with antenatal milk expression. Matern Child Nutr. 2019;15:e12824 https://doi.org/10.1111/ men.12824.

38. Demirci J, Schmella M, Glasser M, Bodnar L, Himes KP. Delayed Lactogenesis $\|$ and potential utility of antenatal milk expression in women developing late-onset preeclampsia: a case series. BMC Pregnancy Childbirth. 2018;18:68 https://doi.org/10.1186/s12884-018-1693-5

39. Fair FJ, Watson $H$, Gardner R, Soltani H. Women's perspectives on antenatal breast expression: a cross-sectional survey. Reprod Health. 2018;15 https:// doi.org/10.1186/s12978-018-0497-4.

40. Lamba S, Chopra S, Negi M. Effect of antenatal breast milk expression at term pregnancy to improve post natal lactational performance. J Obstet Gynecol India. 2016;66:30-4 https://doi.org/10.1007/s13224-014-0648-7.

41. Uikey PA, Agrawal P, Khandale S. Antenatal breast milk expression at term increases postnatal lactational performance. Int J Reprod Contracept Obstet Gynecol. 2017;6:2438 https://doi.org/10.18203/2320-1770.ijrcog20172327.

42. Rietveld CE. Antenatal colostrum harvesting for pregnant women with diabetes in preparation for breastfeeding: Otago Polytechnic; 2011.

43. Clay T. Colostrum harvesting and type 1 diabetes. J Diabetes Nurs. 2005;9: 111-6.

44. Blaikley J, Clarke S, MacKeith R, Ogden KM. Breast-feeding; factors affecting success; a report of a trial of the Woolwich methods in a group of primiparae. J Obstet Gynaecol Br Emp. 1953;60:657-69 https://doi.org/1 0.1111/j.1471-0528.1953.tb07255.x

45. Waller $\mathrm{H}$. The early failure of breast feeding; a clinical study of its causes and their prevention. Arch Dis Child. 1946;21:1-12 https://doi.org/10.1136/a dc.21.105.1.

46. Ingelman-Sundberg A. The value of antenatal massage of nipples and expression of colostrum. BJOG An Int J Obstet Gynaecol. 1958;65:448-9 https://doi.org/10.1111/j.1471-0528.1958.tb08534.x.
47. Brown MS, Hurlock JT. Preparation of the breast for breastfeeding. Nurs Res. 1975;24:448-51 https://doi.org/10.1097/00006199-197511000-00008.

48. Demirci J. Prenatal video-based education and postpartum effects. n.d. https://clinicaltrials.gov/ct2/show/NCT04258709?cond=antenatal+breast+ milk+expression\&draw=2\&rank=1. Accessed 11 Apr 2020.

49. Berger H, On T, Gagnon R, Sermer M, Basso M, Bos $H$, et al. Diabetes in pregnancy. J Obstet Gynaecol Can. 2016;38:667-679.e1 https://doi.org/10.1 016/j.jogc.2016.04.002.

50. Feig DS, Berger H, Donovan L, Godbout A, Kader T, Keely E, et al. 2018 clinical practice guidelines diabetes and pregnancy diabetes Canada clinical practice guidelines expert committee pre-existing diabetes preconception and during pregnancy. Can J Diabetes. 2018;42:S255-82 https://doi.org/10.1 016/j.jcjd.2017.10.038.

51. Narvey MR, Marks SD. The screening and management of newborns at risk for low blood glucose. Paediatr Child Health. 2019;24:536-44 https://doi. org/10.1093/pch/pxz134.

52. Chapman DJ, Perez-Escamilla R. Maternal perception of the onset of lactation is a valid, public health indicator of lactogenesis stage II. J Nutr. 2000;130:2972-80 https://doi.org/10.1093/jn/130.12.2972.

53. Lewallen LP. A review of instruments used to predict early breastfeeding attrition. J Perinat Educ. 2006;15:26-41 https://doi.org/10.1624/1058124 06x92967.

\section{Publisher's Note}

Springer Nature remains neutral with regard to jurisdictional claims in published maps and institutional affiliations.
Ready to submit your research? Choose BMC and benefit from:

- fast, convenient online submission

- thorough peer review by experienced researchers in your field

- rapid publication on acceptance

- support for research data, including large and complex data types

- gold Open Access which fosters wider collaboration and increased citations

- maximum visibility for your research: over $100 \mathrm{M}$ website views per year

At $\mathrm{BMC}$, research is always in progress.

Learn more biomedcentral.com/submissions 